\title{
Bilangan Kromatik Fuzzy dalam Sistem Penjadwalan Fuzzy
}

\author{
Triyani $^{1}$, Siti Rahmah Nurhiami ${ }^{2}$, Niken Larasati ${ }^{3}$, Ari Wardayani ${ }^{4}$ \\ ${ }^{1}$ Jurusan Matematika Universitas Jenderal Soedirman, trianisr@yahoo.com.au
}

\begin{abstract}
Abstrak
Artikel ini bertujuan untuk menemukan bilangan kromatik fuzzy dari graf fuzzy yang dapat merepresentasikan sistem penjadwalan fuzzy. Sistem penjadwalan fuzzy merupakan model penjadwalan yang mempertimbangkan keterbatasan-keterbatasan fasilitas dan sumberdaya sehingga mempunyai penyelesaian yang fleksibel dalam menentukan jumlah interval waktu dalam penjadwalan.Pewarnaan titik pada graf fuzzy dengan menggunakan $\alpha$-cut dapat digunakan untuk menyelesaikan masalah penjadwalan fuzzy. Hasil dari pewarnaan titik pada graf fuzzy dengan menggunakan $\alpha$-cut adalah bilangan kromatik fuzzy yang merupakan himpunan dari pasangan terurut bilangan kromatik crips graph $G_{\alpha}$ dengan $\alpha, \alpha \in[0,1]$.

Kata kunci: graf fuzzy, bilangan kromatik fuzzy, $\alpha$-cut, penjadwalan fuzzy,
\end{abstract}

\begin{abstract}
This article is aimed at finding fuzzy chromatic numbers of fuzzy graphs that can represent fuzzy scheduling systems. Fuzzy scheduling system is a scheduling model that considers the limitations of facilities and resources in scheduling, so that it has a flexible solution in determining the number of time intervals on scheduling. Vertex coloring on fuzzy graphs using $\alpha$-cut can be used to solve fuzzy scheduling problems. The result of vertex coloring on fuzzy graphs using $\alpha$-cut is fuzzy chromatic number. It is a set of ordered pairs of chromatic number of crips graph $G_{\alpha}$ and $\alpha, \alpha \in[0,1]$.

Keywords: fuzzy graph, fuzzy chromatic number, $\alpha$-cut, fuzzy scheduling.
\end{abstract}

\section{PENDAHULUAN}

Penjadwalan (scheduling) merupakan pengalokasian sejumlah kegiatan dan sumber daya pada suatu lembaga dalam interval-interval waktu. Keterbatasan fasilitas, seperti jumlah ruangan yang digunakan, kapasitas ruangan yang berbeda, dosen pengampu mata kuliah, dan banyaknya hari yang dijadwalkan merupakan masalah dalam suatu menjadwalkan perkuliahan. Di samping itu peserta kuliah juga merupakan suatu komponen dalam penjadwalan kuliah yang harus dipertimbangkan. Suatu penjadwalan dikatakan optimal atau efektif, jika tidak terjadi benturan antar komponen-komponen dalam penjadwalan dan jadwal mempunyai jumlah periode penjadwalan minimum.

Pewarnaan graf dalam graf klasik telah digunakan untuk menyelesaikan masalah penjadwalan kuliah [6]. Dalam memodelkan masalah penjadwalan dengan graf ini, hubungan antara

2000 Mathematics Subject Classification: 05C10, 05C15

Submitted: 08-07-2019, Revision: 11-01-2020, Accepted: 30-01-2020. 
104 Triyani dkk, JMI Vol 15 No 2 Okt 2019, pp. 103-110,doi:10.24198/jmi.v15.n2.22372.103-110

dua titik yang merepresentasikan mata kuliah tidak didiskripsikan secara jelas, artinya besar kecilnya keterhubungan dua titik tidak diukur. Desain model graf fuzzy dapat mengatasi ketidakjelasan atau ketidapastian dalam mendiskripsikan hubungan antara dua objek.

Sejak diperkenalkan graf fuzzy oleh Azriel Rosenfeld pada tahun 1975, banyak kajian dalam graf klasik yang digeneralisasi dan dikembangkan baik secara teori maupun aplikasi. Secara aplikasi graf fuzzy dapat dikatakan sebagai suatu topik yang sangat banyak diterapkan baik dalam ilmu-ilmu komputer, ilmu sosial, kesehatan maupun engineering. Munoz et. al [3] telah memperkenalkan $\alpha$-cut pada graf fuzzy dan menggunakan $\alpha$-cut dalam pewarnaan titik pada graf fuzzy. Selanjutnya Dey et.al [1], telah mengaplikasikan pewarnaan titik pada graf fuzzy untuk mengklasifikasikan zona kecelakaan dalam control lalu lintas. Samanta et. al [5] telah menggunakan graf fuzzy untuk jejaring sosial fuzzy. Pada artikel ini didesain sistem penjadwalan fuzzy dan algoritma pewarnaan titik pada graf fuzzy untuk memperoleh bilangan kromatik fuzzy.

Berikut diberikan beberapa definisi yang terkait dengan materi dalam artikel ini.

Definisi 1.1. Misalkan diberikan suatu himpunan tak kosong X. Suatu himpunan fuzzy A dari $X$ didefinisikan sebagai fungsi yang memetakan himpunan ke dalam selang tertutup [0,1] dan dinotasikan dengan $\mu A: X \rightarrow[0,1]$.

Definisi 1.2. Cut-Alpha ( $\alpha$-cut) dari himpunan fuzzy A dinotasikan dengan A $\alpha$ adalah himpunan yang memuat anggota dari $A$ yang mempunyai derajat keanggotaan lebih besar atau sama dengan $\alpha$. Dengan kata lain, $A_{\alpha}=(x \in X \mid \mu A(x) \geq \alpha, \alpha \in[0,1]$.

Definisi 1.3. Misalkan $V$ adalah himpunan tak kosong dan berhingga. Suatu graf fuzzy $G_{F}$ adalah pasangan fungsi $(\alpha, \mu)$ dengan $\alpha$ adalah himpunan fuzzy dari $V$ dan $\mu$ adalah relasi fuzzy simetris pada $\alpha$ sedemikian hingga:

i. $\sigma: V \rightarrow[0,1]$

ii. $\mu: V \times V \rightarrow[0,1]$ yang memenuhi $\mu\left(v_{i}, v_{j}\right) \leq \min \sigma\left(v_{i}\right), \sigma\left(v_{j}\right)$, untuk setiap $v_{i}, v_{j}, \in V$.

Untuk selanjutnya, $\alpha$ disebut sebagai himpunan titik fuzzy dan $\mu$ disebut sebagai himpunan sisi fuzzy. Graf fuzzy dengan himpunan titik fuzzy $\alpha$ dan himpunan sisi fuzzy $\mu$ selanjutnya dinotasikan dengan $G_{F}=(\alpha, \mu)$.

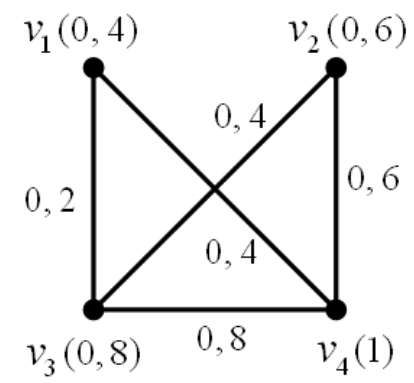

Gambar 1. Graf Fuzzy $G_{F}=(\sigma, \mu)$

Jika semua derajat titik dan sisi dari graf fuzzy $G_{F}$ adalah 1, maka graf fuzzy $G_{F}$ disebut sebagai graf tegas (crips graph) dan dalam gambar derajat keanggotaan titik maupun sisi tidak perlu dituliskan.

Definisi 1.4. Misal $V$ adalah himpunan tak kosong dan berhingga. Untuk $\alpha=[0,1]$, $\alpha$-cut dari graf fuzzy $G_{F}=(\sigma, \mu)$ adalah pasangan terurut $\left(V_{\alpha}, E_{\alpha}\right)$ dimana $V \alpha=v \in V \mid \sigma(v) \geq \alpha$ dan $E_{\alpha}=e \in E \mid \mu(e) \geq \alpha$.

Berdasarkan definisi 4., $\alpha$-cut dari graf fuzzy berupa crips graph $G_{\alpha}=\left(V_{\alpha}, E_{\alpha}\right)$ yang diinduksi dari graf fuzzy $G_{F}$ dengan menghapus semua titik-titik dan sisi-sisi di graf fuzzy 
yang mempunyai derajat keanggotaan kurang dari $\alpha$. Himpunan dari semua $G_{\alpha}=\left(V_{\alpha}, E_{\alpha}\right)$ disebut keluarga dari crips graph $G_{\alpha}=\left(V_{\alpha}, E_{\alpha}\right)$. Gambar 2. berikut adalah keluarga dari $G_{\alpha}=\left(V_{\alpha}, E_{\alpha}\right)$ dengan $\alpha=0,2 ; 0,4 ; 0,6 ; 0,8$ dan 1 untuk Graf fuzzy $G_{F}$ dalam Gambar 1.

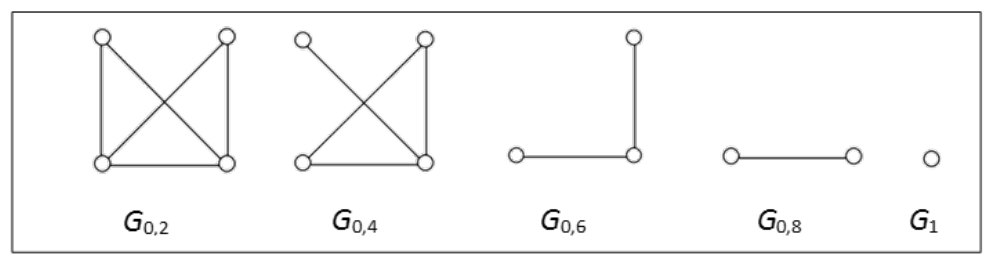

Gambar 2. Keluarga $G_{\alpha}=\left(V_{\alpha}, E_{\alpha}\right)$

Definisi 1.5. Bilangan kromatik fuzzy dari graf fuzzy $G_{F}=(\sigma, \mu)$ adalah bilangan fuzzy $\chi^{f}\left(G_{F}\right)=\left(\chi\left(G_{\alpha}\right), \alpha\right)$ dimana $\chi\left(G_{\alpha}\right)$ adalah bilangan kromatik dari $G_{\alpha}$ dan $\alpha$ adalah derajat keanggotaan titik atau sisi yang berbeda dari graf fuzzy $G_{F}$.

Pewarnaan pada Graf fuzzy merupakan perluasan dari masalah pewarnaan pada graf klasik. Salah satu tipe pewarnaan pada graf fuzzy adalah pewarnaan titik pada graf fuzzy. Munoz et. al [3] telah mengkaji perwarnaan titik pada graf fuzzy dan menggunakan $\alpha$-cut untuk memperoleh bilangan kromatik fuzzy. Dengan menggunakan algoritma Well Powell untuk mewarnai titik pada keluarga crips graph $G_{\alpha}=\left(V_{\alpha}, E_{\alpha}\right)$, diperoleh bilangan kromatik fuzzy $\chi^{f}(G F)$.

Berdasarkan definisi 5 dan menerapkan algoritma Well Powell untuk keluarga crips graph $G_{\alpha}=\left(V_{\alpha}, E_{\alpha}\right)$, diperoleh bilangan kromatik fuzzy pada graf fuzzy gambar 1 adalah $\chi^{f}\left(G_{F}\right)=$ $(4 ; 0,2),(3 ; 0,4),(2 ; 0,6),(2 ; 0,8),(1 ; 1)$.

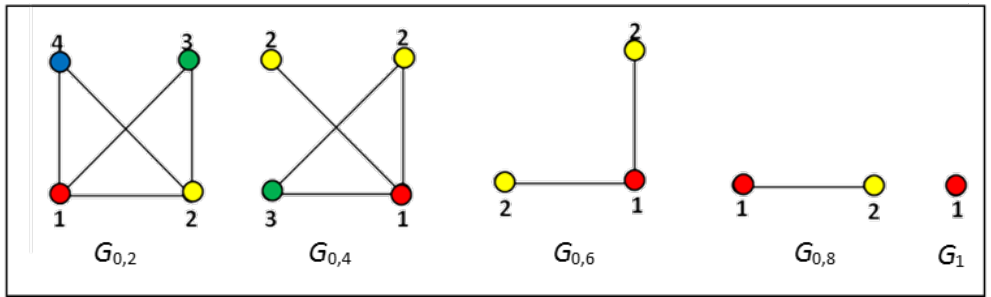

Gambar 3. Pewarnaan titik pada Keluarga $G_{\alpha}=\left(V_{\alpha}, E_{\alpha}\right)$

\section{METODE PENELITIAN}

Metode yang digunakan untuk menyelesaikan permasalahan ini adalah studi literatur dengan langkah awal mengkonstruksikan crips graph $G_{\alpha}$ dari graf fuzzy $G_{F}$, selanjutnya melakukan pewarnaan titik pada $G_{\alpha}$ dengan algoritma Well Powell, dan langkah akhir adalah menentukan bilangan kromatik fuzzy $\chi^{f}\left(G_{F}\right)=\left(\chi\left(G_{\alpha}\right), \alpha\right)$.

\section{HASIL DAN PEMBAHASAN}

3.1. Bilangan Fuzzy dalam Sistem Penjadwalan Fuzzy. Penjadwalan khususnya penjadwalan kuliah, dapat direpresentasikan ke dalam graf fuzzy. Titik fuzzy dapat merepresentasikan sebuah mata kuliah yang ditawarkan baik mata kuliah wajib maupun mata kuliah pilihan dengan nilai/derajat keanggotaan tertentu yang terletak dalam interval $[0,1]$. Titik yang merepresentasikan mata kuliah wajib mempunyai derajat keangotaan 1. Hal ini karena setiap mata kuliah wajib yang ditawarkan pasti diselenggarakan dalam perkuliahan. Sedangkan titik 
yang merepresentasikan mata kuliah pilihan mempunyai derajat keanggotaan yang terletak dalam interval $[0,1]$. Besarnya derajat keanggotaan titik yang merepresentasikan mata kuliah pilihan dapat dihitung berdasarkan perbandingan antara banyaknya mahasiswa yang mengikuti mata kuliah tersebut dengan maksimum banyaknya mahasiswa yang mengikuti mata kuliahmata kuliah dalam satu semester tersebut. Semakin banyak mahasiswa yang mengambil suatu mata kuliah pilihan tertentu, maka derajat keanggotaan titiknya semakin mendekati 1 . Jika terdapat mata kuliah pilihan yang ditawarkan tetapi tidak ada mahasiswa yang mengambil, maka derajat keanggotaan titiknya adalah nol. Sisi fuzzy dapat merepresentasikan hubungan ke dua mata kuliah, jika ke dua mata kuliah diikuti oleh satu atau lebih mahasiswa yang sama maka ke dua titik tersebut dihubungkan, namun jika ke dua mata kuliah diikuti oleh mahasiswa yang berbeda maka tidak ada sisi yang menghubungkan ke dua titik tersebut. Derajat keanggotaan sisi yang terletak di antara interval tutup [0,1] dalam graf fuzzy ini dihitung berdasarkan perbandingan antara banyaknya mahasiswa yang sama yang mengikuti dua mata kuliah yang berkaitan dengan minimum banyaknya mahasiswa yang mengikuti dua mata kuliah tersebut.

Misal terdapat $n$ mata kuliah yang ditawarkan pada satu semester dan titik $v_{i}$ merepresentasikan sebuah mata kuliah $i=1,2,3, \ldots, n$. Misalkan pula banyaknya mahasiswa yang mengambil mata kuliah $v_{i}$ dan $v_{j}$ masing-masing adalah $m_{i}$ dan $m_{j}$. Jika $x$ menyatakan banyaknya mahasiswa yang sama yang mengambil mata kuliah $v_{i}$ dan $v_{j}$ sekaligus, maka derajat keanggotaan titik $\sigma\left(v_{i}\right)$ dan sisi $\mu\left(v_{i}, v_{j}\right)$ dapat dimodelkan dengan persamaan

$$
\begin{aligned}
& \sigma\left(v_{i}\right)= \begin{cases}1, & v_{i} \text { mata kuliah wajib } i=1,2, \ldots, n \\
\frac{m_{i}}{\max \left\{m_{1}, m_{2}, \ldots, m_{n}\right\}}, & v_{i} \text { mata kuliah pilihan }\end{cases} \\
& \mu\left(v_{i}, v_{j}\right)=\frac{x}{\min \left\{m_{i}, m_{j}\right\}}, 0 \leq x \leq \min \left\{m_{i}, m_{j}\right\}
\end{aligned}
$$

Asumsi-asumsi yang membatasi permasalahan dalam sistem penjadwalan fuzzy ini adalah

(1) Mata kuliah yang dimaksud adalah mata kuliah dalam satu semester yang penyelenggaraannya membutuhkan ruang kelas.

(2) Derajat keanggotaan titik selalu lebih besar dari derajat keanggotaan sisi. Hal ini dilakukan untuk menghindari penghapusan titik yang mempunyai derajat keanggotaan kurang dari $\alpha$.

(3) Jika terdapat satu mata kuliah yang diselenggarakan dua kali/minggu maka direpresentasikan dalam dua titik yang berbeda.

Berdasarkan model penjadwalan fuzzy dalam persamaan (1) dan (2), maka model tersebut dapat direpresentasikan ke dalam matriks simetri $\mu$ yang elemen-elemen matriks baris ke $i$ kolom ke $j$ nya adalah $\mu\left(v_{i}, v_{j}\right)$. Matriks simetri $\mu$ merupakan matriks simetri berukuran $n \times n$ yang dapat dikontruksi menjadi graf fuzzy $G_{F}$. Selanjutnya dari graf fuzzy ini dapat ditentukan bilangan kromatik fuzzy $\chi^{f}\left(G_{F}\right)$. Dalam penjadwalan fuzzy, bilangan kromatik fuzzy ini selanjutnya disebut bilangan fuzzy yang merepresentasikan jumlah periode penjadwalan beserta keterbatasan fasilitas-fasilitas dalam penjadwalan.

3.2. Algoritma pewarnaan titik pada Graf fuzzy untuk sistem penjadwalan fuzzy . Misal diberikan himpunan tak kosong $V$ dengan $|V|=n$ dan graf fuzzy $G_{F}=(\sigma, \mu)$ dengan $\sigma(v)=1$ untuk setiap $v \in V$ serta $\mu: V \times V \rightarrow[0,1]$. Algoritma pewarnaan titik pada graf fuzzy $G_{F}$ dalam sistem penjadwalan fuzzy menggunakan $\alpha$-cut adalah sebagai berikut:

(1) Bentuk matriks $\mu=\left({ }_{i j}\right)$ berukuruan $n \times n$, dengan

$$
\left(\mu_{i j}\right)= \begin{cases}\mu\left(v_{i}, v_{j}\right), & \text { untuk } v_{i}, v_{j} \in E \\ 0, & \text { untuk yang lainnya }\end{cases}
$$

dan

$$
\mu\left(v_{i}, v_{j}\right)=\frac{x}{\min \left\{m_{i}, m_{j}\right\}}, 0 \leq x \leq \min \left\{m_{i}, m_{j}\right\}
$$

$m_{i}$ menyatakan jumlah mahasiswa yang mengambil mata kuliah $i$

$m_{j}$ menyatakan jumlah mahasiswa yang mengambil mata kuliah $j$ dan 
$x$ menyatakan jumlah mahasiswa yang sama mengambil mata kuliah $i$ dan $j(i, j=$ $1,2, \ldots, n)$.

(2) Tentukan $V_{1}=\{v \in V \mid \sigma(v)=1\}=\left\{v_{1}, v_{2}, \ldots, v_{n}\right\}$

(3) Tentukan $E_{\alpha}=\left\{\left(v_{i}, v_{j}\right) \mid v_{i}, v_{j} \in V, \mu\left(v_{i}, v_{j}\right) \geq \alpha\right\}$

(4) Konstruksikan graf fuzzy $G_{F}=(\sigma, \mu)$

(5) Pilih $\alpha \in[0,1]$

(6) Konstruksi graf tegas $G_{\alpha}=\left(V_{1}, E_{\alpha}\right)$

(7) Lakukan proses pewarnaan titik pada graf tegas $G_{\alpha}=\left(V_{1}, E_{\alpha}\right)$ dengan Algoritma Welch Powell.

(8) Ulangi langkah 5 sampai semua $\alpha$ terpilih

(9) Tentukan bilangan kromatik fuzzy $\chi^{f}\left(G_{F}\right)=\left\{\chi\left(G_{\alpha}\right), \alpha\right\}$

(10) Selesai

Simulasi hasil pemrograman bilangan kromatik fuzzy dengan menggunakan software MATLAB untuk matriks $\mu$ berukuran $32 \times 32$ diberikan pada gambar 4, 5, 6 dan 7 berikut.

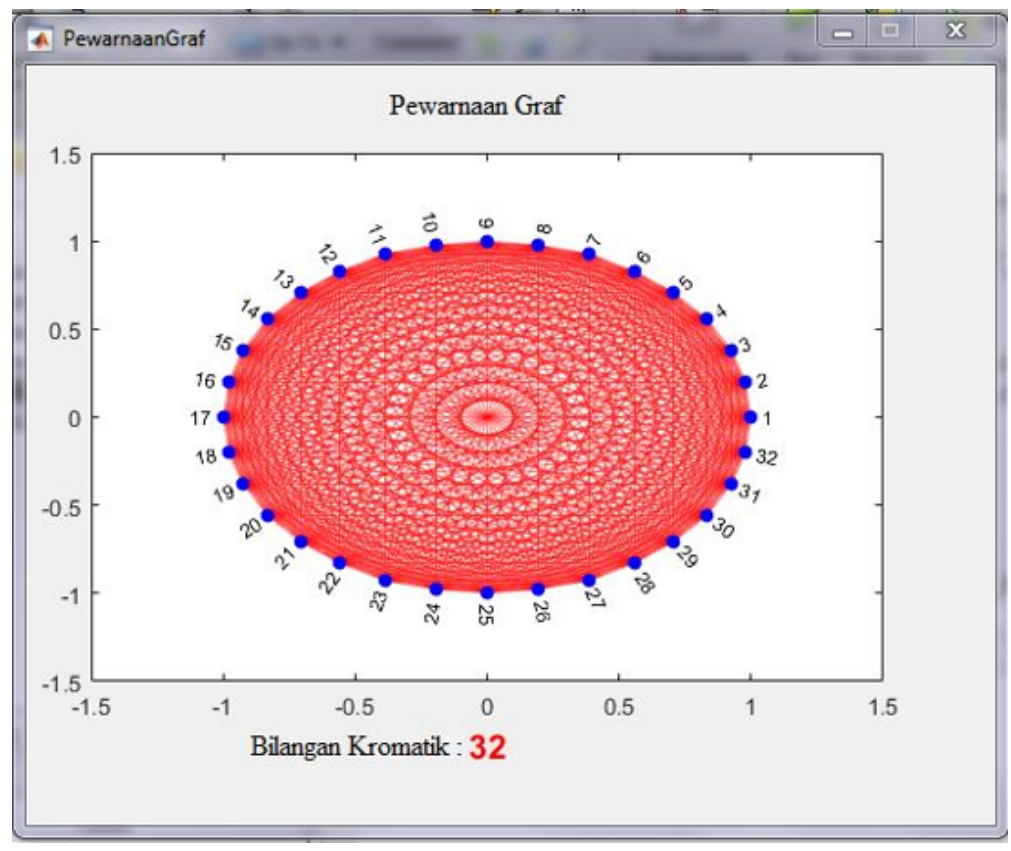

Gambar 4. Tampilan pewarnaan graf $G_{\alpha}$ untuk $\alpha=0$

Berdasarkan Gambar 4., $G_{0}$ adalah graf lengkap. Karena setiap titik terhubung dengan setiap titik yang lainnya, maka terdapat 32 warna (dilabelkan dengan angka 1 sampai dengan 32 pada titik-titik di graf lengkap $G_{0}$ ). Hal ini berarti terdapat 32 periode waktu yang harus dijadwalkan agar dalam penyelenggaraan perkuliahan tidak terjadi benturan dua mata kuliah yang diikuti oleh minimal satu mahasiswa yang sama dijadwalkan secara bersamaan.

Jika sisi-sisi yang mempunyai derajat keanggotaan kurang dari 0,1 diabaikan, maka bilangan kromatik yang dihasilkan adalah $\chi\left(G_{0,1}\right)=10$, seperti tampak pada gambar 5 berikut. 


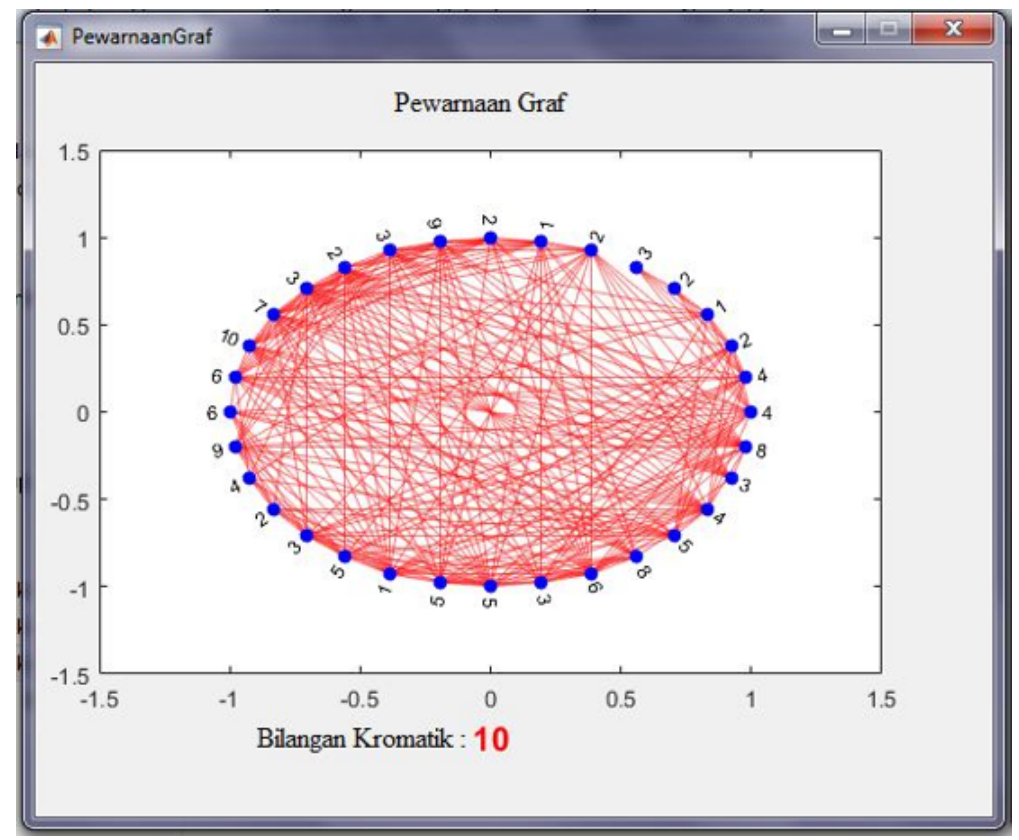

GAmBAR 5. Tampilan pewarnaan graf $G_{\alpha}$ untuk $\alpha=0,1$

Berdasarkan Gambar 5. diperoleh bilangan kromatik 10, jika sisi-sisi dengan derajat keanggotaan kurang dari 0,1 dihapus. Akibatnya bilangan kromatik yang diperoleh menjadi lebih kecil. Dalam penjadwalan, hal ini berarti jumlah mahasiswa yang sama mengikuti dua mata kuliah berbeda berjumlah kurang dari $10 \%$, diabaikan, mengakibatkan jumlah interval waktu dalam penjadwalan menjadi lebih sedikit.

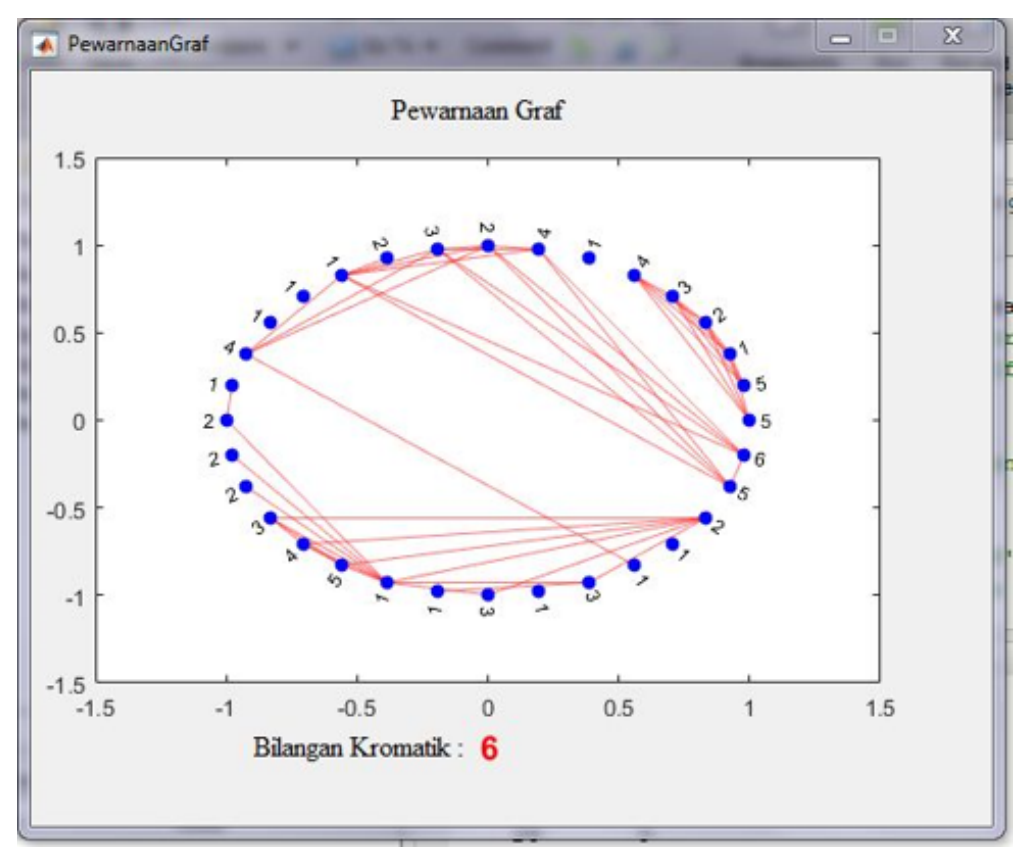

Gambar 6. Tampilan pewarnaan graf $G_{\alpha}$ untuk $\alpha=0,65$ 


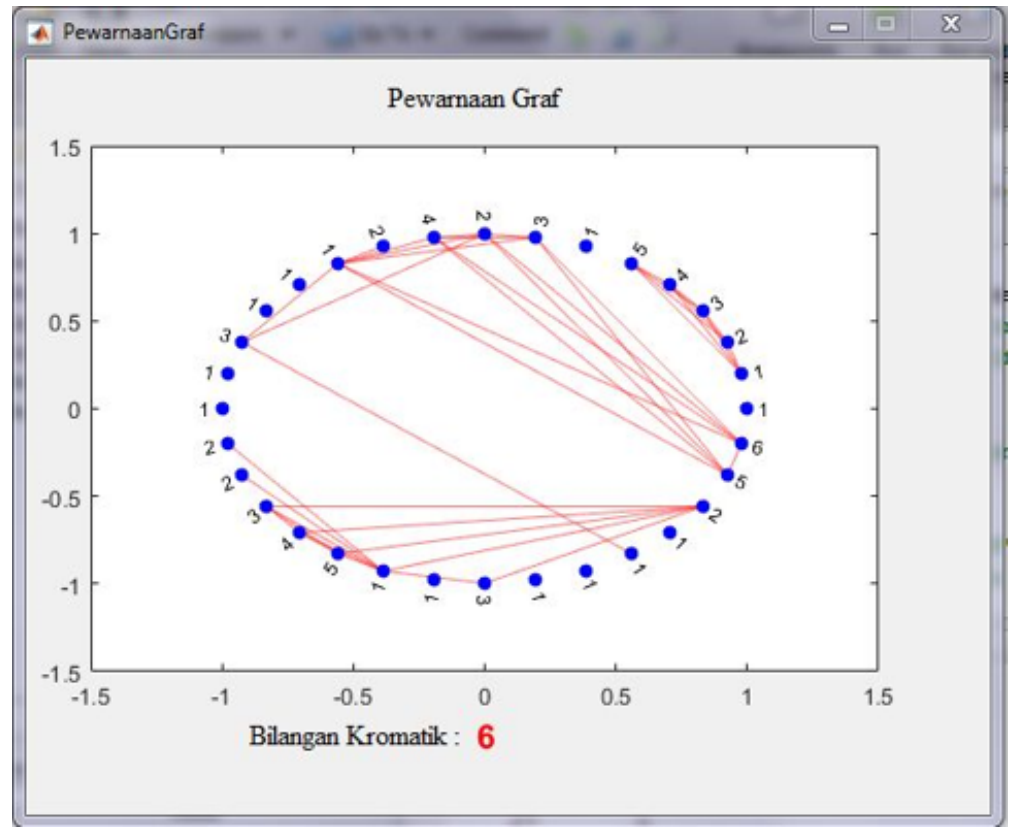

GAmBAR 7. Tampilan pewarnaan graf $G_{\alpha}$ untuk $\alpha=0,702$

Tampilan pada Gambar 6 dan 7 adalah hasil pewarnaan untuk $\alpha=0,65$ dan $\alpha=0,702$ dengan bilangan kromatik $\chi\left(G_{\alpha}\right)=6$.

Berdasarkan hasil simulasi dapat disimpulkan bahwa bilangan kromatik crips graph $\chi\left(G_{\alpha}\right)$ bergantung pada nilai $\alpha$. Bilangan kromatik fuzzy merupakan pasangan antara bilangan kromatik $G_{\alpha}$ dengan $\alpha$. Dalam penjadwalan, bilangan kromatik fuzzy merepresentasikan beberapa alternative penjadwalan berdasarkan jumlah periode waktu yang diinginkan. Jumlah periode waktu dalam penjadwalan dapat disesuaikan dengan ketersediaan fasilitas fasilitas dalam penjadwalan.

\section{SIMPULAN DAN SARAN}

\subsection{Simpulan.}

(1) Bilangan kromatik fuzzy dalam sistem penjadwalan fuzzy diperoleh dari pewarnaan titik pada graf fuzzy $G_{F}=(\sigma, \mu)$ menggunakan $\alpha$-cut dengan derajat keanggotaan semua titiknya sama dengan 1.

(2) Bilangan kromatik fuzzy dalam sistem penjadwalan fuzzy merupakan himpunan yang memuat pasangan terurut $\left(\chi\left(G_{\alpha}\right), \alpha\right)$, dengan $\alpha \in[0,1]$ dengan $\chi\left(G_{\alpha}\right)$ merupakan bilangan kromatik dari crips graph $G_{\alpha}$.

(3) Bilangan kromatik fuzzy dalam sistem penjadwalan fuzzy merupakan himpunan dari bilangan-bilangan yang dapat merepresentasikan beberapa jumlah periode dalam penjadwalan. Dengan bilangan kromatik fuzzy ini diperoleh sistem penjadwalan yang fleksibel dalam menentukan jumlah periode penjadwalan karena jumlah periode tergantung dari ketersediaan fasilitas dan sumber daya dalam sistem penjadwalan.

4.2. Saran. Artikel ini terbatas hanya pada menyusun algoritma dan menentukan bilangan kromatik fuzzy dari graf fuzzy secara simulasi dengan bantuan software MATLAB. Saran untuk penelitian berikutnya adalah menerapkan algoritma ke dalam penyusunan jadwal perkuliahan.

\section{DAftar Pustaka}

[1] Dey, A. dan Anita Pal, 2013, Fuzzy Graph Coloring Techniq to Classify the Accidental Zone of a Traffic Control, Annals of Pure and Applied Mathematics, Vol. 3., No. 2, pp 169-178 (2013). 
110 Triyani dkk, JMI Vol 15 No 2 Okt 2019, pp. 103-110,doi:10.24198/jmi.v15.n2.22372.103-110

[2] Mordeson, J.N dan Nair, P.S. 2000, Fuzzy Graphs and Fuzzy Hypergraphs. Heidelberg. Pyisica-Verlag.

[3] Munoz S, Ortuno M.T, Javier R, Yanez J., 2005. Colouring Fuzzy Graph. The Journal of Managemen Science 33: 211-221(2005).

[4] Rosenfeld, A. 1975. Fuzzy Graphs, In Zadeh, L.A. et al. Fuzzy Sets and Their Applications, Academic Press. pp. 77-95 (1975).

[5] Samanta dan Pal, J., 2013. Telecommunication System Based on Fuzzy Graphs. Journal of Telecommunications System \& Management. Vol. 3. ISSN: 2167-0919 JTSM (2013).

[6] Sunarni T., 2017, Optimasi Penjadwalan Mata Kuliah Menggunakan Pewarnaan Graf, Prosiding SNTI dan Satelit, pp E48-53 (2017).

[7] Sunita, M.S. dan Mathew, S. 2013. Fuzzy Graph Theory : A Survey. Annals of Pure and Applied mathematics. Vol. 4, No.1. pp 92-110 (2013).

[8] Zadeh, L.A. 1965. Fuzzy Set. Journal of the Information and Control, 8, pp.338-353 (1965). 